\title{
THEISM AND MEANING IN LIFE
}

\section{JOHN COTTINGHAM}

\author{
University of Reading \& Heythrop College
}

\section{I. 'NATURE' AND THE PITFALLS OF 'NATURALISM'}

Propositions are important in philosophy, but so are prepositions. All of us want, and indeed need, to find meaning in our lives: this is part of what it is to be human. But is there also a deeper human desire and need to find the meaning of life? I myself think there is; though I am aware that the 'of' formulation is objectionable to many, since it appears to point to something outside of, or beyond, human life, something 'external', towards which it is or should be directed, and which supposedly makes it meaningful. One is reminded here of Wittgenstein's famous remark, Der Sinn der Welt muß außerhalb ihrer liegen - the sense, or meaning, of the world must lie outside it. ${ }^{1}$ Thaddeus Metz's comprehensive and meticulously argued book is, significantly, titled Meaning in Life, and indeed on the jacket cover the preposition 'in' is typeset in such as way as to give it special emphasis. ${ }^{2}$ The stance taken by Metz is what one might call 'immanentist', in the sense delineated by Adrian Moore in his discussion of the ideas of three notable champions of immanence, Baruch Spinoza, Friedrich Nietzsche and Gilles Deleuze:

At the heart of what they most fundamentally share is a celebration of activity, an affirmation of life, in all its diversity. [They reject] the idea that life needs somehow to be justified, whether by some telos towards which everything is striving or by some transcendent structure in terms of which everything makes sense. Nature has no grand design. Nor is

${ }^{1}$ Ludwig Wittgenstein, Tractatus Logico-Philosophicus [1921] (London: Routledge, 1961), $\$ 6.41$.

2 Thaddeus Metz, Meaning in Life. An Analytic Study (Oxford: Oxford University Press, 2013). 
there anything transcendent to it. The celebration of activity and the affirmation of life are the celebration and the affirmation of immanence. ${ }^{3}$

The way Metz articulates what might be called the 'immanentist' stance is to say that 'meaning is possible in a purely natural world, and indeed in the context of what is more or less available to human beings' (p. 247, emphasis supplied). ${ }^{4}$ He may not, of course, agree with all or any of the particular philosophical theses advanced by Moore's trio, Spinoza, Nietzsche, and Deleuze, but he does clearly subscribe to the idea that the 'purely natural world' is all there is, and that we had better find what meaning we can within this world. And this in turn explains why he devotes a very substantial portion of the book to unpacking and criticising what he calls 'supernaturalist theories' of meaning in life, within which category he includes my own work, which he discusses at length.

I am most grateful for the attention Metz has given to my views, but I must voice a certain initial disquiet about being classified as a 'supernaturalist'. 'Supernatural' seems to me a very unsatisfactory term, and it's one that I have increasingly tried to avoid in my writings; indeed in On the Meaning of Life I mention it only three times, each time going on to register qualms about it. ${ }^{5}$ One of the problems with 'supernatural' is that it is a kind of blank, a placeholder (rather like 'non-material'): it purports to classify or inform, but actually it tells us little or nothing about the item so described. Clearly the God of traditional theism is conceived of as having personal characteristics (such as compassion and faithfulness), so has to be thought of as a person, or as analogous to a person; but to add that he is a 'supernatural' person is unlikely to do much more for most people than to conjure up some vague and distinctly unhelpful notion of a Cartesian ghost or disembodied spirit. ${ }^{6}$ In any case, the term 'supernatural' implies a sharp antithesis between God and nature which is itself distinctly unsatisfactory. For 'nature' is a highly ambiguous term - one often used nowadays in a very restricted

\footnotetext{
${ }^{3}$ Adrian Moore, The Evolution of Modern Metaphysics: Making Sense of Things (Cambridge: Cambridge University Press, 2012), pp. 248-9.

${ }^{4}$ Unattributed page references in parentheses in the main text refer to Metz, Meaning in Life (see note 2, above).

${ }^{5}$ John Cottingham, On the Meaning of Life (London: Routledge, 2003), pp. 75, 87, 92.

${ }^{6}$ It's significant that Metz often characterizes supernaturalism as comprising 'Godcentred' and 'soul-centred' approaches to meaning in life. For my own part, I try to avoid the term 'soul' in my work, since I find that its dualistic connotations (to the modern philosophical ear) make it as problematic as the term 'supernatural'.
} 
sense to refer to the empirical world as described by the language of science (hence the contemporary philosophical use of 'naturalism' to mean the view that nothing ultimately exists but the physical world). It is not entirely clear to me how far Metz is drawn to this kind of scientistic naturalism; but there are places where it almost seems as if he has, as they say, 'drunk the Kool-Aid' and subscribed to the over-exalted view of what science can do that is so prevalent in contemporary analytic philosophy, as when he dismisses the lingering longing for something greater than what is available to us human beings, as we are known by scientific means' (p. 247, emphasis supplied).

I would say that a very large part of what is interesting and important about us cannot be known through the methods and procedures of science. Indeed, the 'humane' turn in philosophy that I have been advocating in recent years is in part an attempt to argue that understanding the human predicament requires all the resources of the human mind. A philosophical worldview, if it is to be tenable at all, must not just engage our intellectual and scientifically oriented faculties and abilities, but must take account of all the ways in which we respond to the world, including our emotional and imaginative modes of awareness. Many philosophers in the past have tended to discount these responses, preferring to take refuge in theoretical abstractions that put them at a certain superior distance from the phenomena they are supposed to be understanding. But such distance is achieved at a cost. It's almost as if there is a hypertrophy of the 'left-brain' skills whereby we analyse and classify and dissect phenomena, without proper scope being accorded to the 'right brain' skills that facilitate more intuitive and holistic forms of cognition. ${ }^{7}$ Logical and scientific analysis is but one way of understanding the human condition, and to restrict our philosophical toolkit to this domain can lead to a radically impoverished conception of ourselves and the cosmos we inhabit.

To come back to the term 'nature', I would wholeheartedly agree with Metz that the pursuit of meaning is 'fundamental to our human nature, and that this search comprises 'much of what we most prize and are willing to make sacrifices for', including such things as 'justice, art, beauty' (p. 249). But a proper explication both of our own 'nature', as beings who

7 See John Cottingham, Philosophy of Religion: Towards a More Humane Approach (Cambridge: Cambridge University Press, 2014). For the contrast between what may, as a convenient shorthand, be called 'left-brain' and 'right-brain' modes of awareness, see Iain McGilchrist, The Master and his Emissary (New Haven: Yale University Press, 2009). 
pursue these things, and of the 'nature' of the values we pursue, will take us far outside the domain of what can be known by 'scientific means. The 'nature' we are investigating will be nature in a far richer sense than what is described by the quantitative printouts of mathematical science, or the explanatory theories of the life-sciences, or even the social sciences (if there are any). And a crucial question will now arise as to how our worldview can accommodate this 'enriched nature' that confronts us, ${ }^{8}$ a reality that is shot through with meaning and value.

The theistic take on this, of course, is that our cosmos is pervaded by the presence of the divine, the ultimate reality in whom, in St Paul's phrase, we 'live and move and have our being.' One of the most important ways of understanding God, for the theist, is through the natural world, the wonders and beauties of which give us 'intimations of the transcendent.' ${ }^{10}$ So nature is not the just the blank impersonal configuration of particles and forces described by modern physics, but comprises the magnificent whirling blaze of the galaxies, the wild rolling of the oceans, and the shimmering green of the woods in Spring. The world, the natural world, is, for the theist, 'charged with the grandeur of God', as Gerard Manley Hopkins famously put it. ${ }^{11}$ To label God as 'supernatural' is thus to risk removing him from the very manifestation of the sacred here in the natural world which is one of our most important modes of access to the divine. ${ }^{12}$

\section{THE BASIS OF MORAL VALUE}

I am often struck by the surprising amount of common ground between the theistic outlook and the outlook of philosophers like Metz who hold there is an objective basis for the value and meaning we find in the world. Metz, I take it, believes, as I do, in objective moral norms that are not reducible to our desires or preferences, not merely inclinations or commitments that we mistakenly project onto reality, but genuine,

\footnotetext{
${ }^{8}$ See Fiona Ellis, God, Value, and Nature (Oxford: Oxford University Press, 2014).

${ }^{9}$ Acts 17:28.

${ }^{10}$ See John Cottingham, 'Human Nature and the Transcendent', Philosophy, supplementary volume 70 (2012); and Cottingham, Philosophy of Religion, Ch. 3, sectn 4.

${ }^{11}$ From Gerard Manley Hopkins, Poems (1876-1889), in W. H. Gardner (ed.), The Poems and Prose of Gerard Manley Hopkins (Harmondsworth: Penguin, 1953).

${ }^{12}$ For more on this, see John Cottingham, How to Believe (London: Bloomsbury, 2015).
} 
authoritative, universal and binding requirements that we are obliged to follow, whether we like it or not, and which remain binding even when, as so often, we fail to act on them. But those who have such a firm belief in the universal and objective status of moral norms seem to me to be taking a view of the true nature of reality whose implications bring them very close to the theistic worldview, as I hope will appear shortly.

First, though, there are two basic objections that Metz has, as I see it, to a theistic account of the status of such objective moral norms. The first is a consistency problem. Consider a moral truth such as that cruelty is wrong, or that compassion is required of us. We know such truths, Metz points out, with greater certainty than we know that there is a God. Yet this makes the theistic moral theorist's position incoherent, according to Metz, since if God is to be the basis for cruelty's being wrong, or compassion's being required, 'the evidence for both must be comparable' (p. 90). In other words, the evidence for God ought to be as strong as the evidence of these moral requirements, yet that is patently not so. This objection is supposed to have force not just against my position, but against that of anyone who holds that rightness and wrongness have their basis in God.

Ihave to confess to being puzzled by the 'parity of evidence' requirement that Metz wishes to impose here. After all, scientists frequently propose that some manifest feature of the world $M$ is a function of some theoretical entity $T$, but they are surely not logically committed to saying that the evidence for both must be comparable. Theoretical entities such as quarks are often problematic items that are shrouded in obscurity, and certainly not as palpable as the ordinary observable things (apples and pears) they are posited in order to explain. ${ }^{13} \mathrm{God}$, in the traditional

${ }^{13}$ This is essentially the response I made when Metz first formulated this type of objection to a theistic metaethics. See his 'God, Morality and the Meaning of Life', in N. Athanassoulis and S. Vice (eds), The Moral Life: Essays in Honour of John Cottingham (Basingstoke: Palgrave Macmillan, 2008), p. 212; and my 'The Self, the Good Life and the Transcendent', same volume, p. 266. Metz takes up the debate again in Meaning in Life, pp. 96-7, but I have to say that my puzzlement about the 'parity of evidence' requirement remains. In these later remarks Metz allows that one who takes my position may coherently be more confident that wrongness exists than that God exists (p. 97), but insists my position must be formulated in stronger terms than mere degrees of confidence: 'the relevant principle is one that appeals to differential knowledge' (p. 96). The point seems to be that my claim that God is the basis of moral requirements must be a claim to conclusive knowledge, but I am unclear as to why my position has to be formulated in this epistemically maximal way. 
theistic picture, is shrouded in even greater obscurity than the posited entities of theoretical science, dwelling, as the Scriptures have it, in 'light inaccessible, whom no man hath seen nor can see' (I Timothy 6:16; cf. Exodus 33:20). Yet the divine reality is, for all that, supposed by the believer to be glimpsed in the nature of the reality we inhabit, a reality whose nature includes the existence of moral constraints that are not derivable from the natural world as described by the scientist.

A complication in this debate which is perhaps worth mentioning (though it takes us onto a slightly different tack from the last paragraph) concerns the notion of 'evidence', which Metz tends to construe along strict scientific lines - as what might be called 'spectator evidence', to use Paul Moser's apt expression. ${ }^{14}$ In my more recent work, I have argued that the theistic outlook is based not on an 'epistemology of detachment', but on an 'epistemology of receptivity': that is to say, unlike the data which serve to confirm the theories of the scientist, the kinds of evidence relevant to religious faith are those that require certain transformations in the subject in order to make themselves manifest. ${ }^{15}$ There is no space to develop these ideas here, but they may make a difference to some of the moves Metz makes in combating the claims of theism to underwrite morality. For example, he observes that any appeal to subjective experience in this kind of context would face the problem that 'not many of this book's readers will have had such religious experiences', and that where such experiences do occur, they are unlikely to manifest sufficient convergence to count as proper evidence (p. 90, footnote, emphasis supplied). But there are many genuine phenomena (consider the properties of a complex piece of classical music) which are such that by no means every detached and rational observer (or listener) will apprehend them, or apprehend them in the same way. Everything depends on the right kind of receptivity. Complex training and transformation in the subject are required for the relevant musical properties to be discerned. And hence the evidence may be neither widely available nor uniform across different groups; but the apprehension of the properties in question, when it does occur, may nonetheless reasonably be considered authentic and authoritative.

${ }^{14}$ Paul Moser, The Elusive God: Reorienting Religious Epistemology (Cambridge: Cambridge University Press, 2008), p. 47.

${ }^{15}$ Cottingham, Philosophy of Religion, Ch. 1; How to Believe, Ch. 1 and Ch. 3. 
Metz's second main reason for rejecting the theistic account of moral requirements is that he considers there is a 'more coherent meta-ethical position' that is available, one that preserves parity of evidence between the manifest moral requirements, on the one hand, and what explains them, on the other. This is the view that moral requirements are a function of natural properties. 'Given that we do not know that a spiritual realm exists, and given that we do know that matter exists, a naturalist absolute morality would fit much better with what else we think we know about the world' (p. 91). And hence a naturalist metaphysics is a much better candidate than a theistic one for underwriting what Metz terms an 'absolute' ethical system (one involving objective universal necessary normative truths).

The type of naturalism that Metz favours in this context is not a crude reductive naturalism (for example one that deflates moral requirements into mere subjective preferences, or disguised hedonic drives). Instead, it is a species of moral realism (sometimes known as 'Cornell realism') that is analogous to scientific realism. On this view, moral truths express synthetic a posteriori necessities (analogous to scientifically established natural-kind identities, like 'water is $\mathrm{H}_{2} \mathrm{O}$ '). Thus it is supposed that just as we have discovered that water is identical to $\mathrm{H}_{2} \mathrm{O}$, so, for example, "we have learned empirically over time that our terms "wrongness" and "degradation of persons" essentially refer to one and the same class of actions [so as to make it] universally, objectively and necessarily true' that it is wrong to degrade people (p. 92).

The analogy with 'water is $\mathrm{H}_{2} \mathrm{O}$ ' does not initially look very promising, since this particular scientific identity claim, unlike what we find in the moral case, involves an identity of composition (water droplets are made up of molecules composed of hydrogen and oxygen atoms). But this is only the start of the trouble. A deeper worry is that moral requirements are just that, requirements: they have normative or authoritative force, calling upon us to act or refrain from acting in certain ways. And here the analogy with the empirical discoveries of physics, on the one hand, and the kind of 'realism' expressed by synthetic identity statements about rightness or wrongness, on the other, seems to break down entirely. Metz acknowledges this kind of worry, but takes the objection to boil down to the complaint that 'moral language is not reducible to the language of [...] sense-based inquiry' (p. 93); and he replies that the moral realist under discussion does not need to maintain that normativity can be 
apprehended directly through one of the five senses (any more than the scientific realist has to maintain that we literally see causation). It is not a question of what can be directly detected via the senses, Metz argues, but rather of the metaphysical status of the properties in question. Just as the scientific realist can maintain that causation is a physical relation, so the naturalist in meta-ethics can maintain that 'normativity is a physical relation', even though neither normativity nor causation can be directly observed through the five senses. ${ }^{16}$ Metz summarizes his position by saying that 'at the core, naturalism is a metaphysical thesis about what exists (only the physical), and, in the meta-ethical realm, about the nature of ethical properties (they are physical)' (p. 93).

The term 'physical' is, to begin with, a difficult one, since it is going to have to embrace rocks and stones and molecules and atoms and quarks and quantum fluctuations; and when one looks at the profoundly heterogeneous nature of the items in such a list, one begins to suspect that they are going to have nothing in common beyond that they figure in the descriptions and theories of natural scientists. But in any case, nothing in the physical world as normally conceived could possibly embrace the idea of something's being incumbent upon us, of something's being an authoritative requirement that requires our allegiance, irrespective of the actual empirical configuration of natural desires and inclinations and preferences that we happen to have. At this point, I suppose, the metaethical realist-naturalist could say that reality is stranger than we might suppose: just as there are weird and surprising quantum properties floating around, waiting to be identified by empirical investigation, so the cosmos contains normative properties, similarly waiting our investigative inquiry.

But notice the claim that is being made, or implied, here. The claim is that reality, in its essential nature, is such as to make authoritative normative demands upon us. Reality, as Hilary Putnam has put it, is 'not morally indifferent.' ${ }^{17}$ Yet once we have got this far, it should perhaps begin to be clear why I began this section by observing that the

${ }^{16}$ At least if we accept David Hume's view of causation. Hume famously thought that we only observe successive correlations, never causal transactions as such (A Treatise of Human Nature [1739-40], ed. by D. F. and M. J. Norton (Oxford: Oxford University Press, 2000), Bk I, Part 3, Section 14. Contrast R. Harré and C. Madden, Causal Powers (Oxford: Blackwell, 1975).

${ }^{17}$ Hilary Putnam, Jewish Philosophy as a Guide to Life (Bloomington: Indiana University Press, 2008), p. 6. 
implications of Metz's defence of this kind of position (concerning the real objective status of moral norms) appear to bring him surprisingly close to the theistic picture. For to say that reality has this fundamentally and essentially moral or normative nature seems to be precisely the kind of claim that traditional theism has been making all along. If one counters by saying that the naturalist-realist view under discussion is radically different, and much more down-to-earth, because the relevant moral properties are essentially identical with physical properties, then one will have to explain how a purely physical property can be such as to instantiate this kind of normative power (whereas it is no mystery how a certain molecular structure could be such as to instantiate the property of wateriness). ${ }^{18}$ I suspect that in the end the attractiveness of this kind of scientifically modelled 'moral realism' is less a function of its explanatory force than its conformity with the metaphysical dogma that 'only the physical exists'. I put this perhaps over strongly; but it does seem to me a curious feature of the contemporary philosophical climate that a (fully justified) admiration for the achievements of natural science has led so many otherwise sober and acute philosophical thinkers to try to trim all of reality to a Procrustean physicalist bed that much of it patently does not fit.

\section{TRANSCENDENCE AND TELEOLOGY}

Let me end, briefly, by recording my broad concurrence with the substantive account Metz provides of the values which make for a meaningful life. What he calls his 'fundamentality' theory is notable for its resolute rejection of wholly subjectivist accounts of meaningfulness (which I agree with him have 'deeply counterintuitive' implications (p. 220)); and it also seems to me admirable in its insistence that a meaningful life is one that must be rationally oriented towards what is objectively true, good, and beautiful (pp. 227-232), where 'reason' and 'rationality' are construed broadly, so as to encompass affective and desiderative aspects of our human nature that are responsive to rational

18 To gloss this normative power as the power of providing us with all-thingsconsidered overriding reasons to act in certain ways independently of our desires and interests (cf. Metz, p. 93) seems to me to highlight the problem rather than to mitigate it. A physical property might, to be sure, provide a prima facie reason for my acting in a certain way, given that I have certain desires or objectives, but this falls far short of the strong overriding normative authority envisaged. 
deliberation (p. 223). Another important plus is that the Metz account of a meaningful life has what one might call a 'holistic' character, which he construes in terms of a meaningful life's having 'narrative value' when taken as a whole (though the precise details of how this is to be achieved are, reasonably enough, left as an agenda for future reflection).

The overall framework within which this account is situated is a conception of the 'deep or profound concerns' (p. 219) that make human life worth living; or, to use another formulation employed by Metz, the account is 'grounded' by an appeal to 'deep facets of human life' (p. 219), or 'fundamental conditions of human existence' (p. 235). There is, a seriousness of commitment in all this, and a kind of ultimately positive vision of the human condition, which for me makes Metz's outlook seem very close to a religious one (though he may not like this label, and might perhaps prefer 'quasi-religious'). But I can perhaps bring out something of what I mean here by quoting a passage from Bernard Williams, which points in a very different direction, and encapsulates just why, to many in the modern age, the quest for a meaningful life for humans seems unlikely achieve a satisfactory outcome:

[The]most plausible stories now available about [human] evolution, including its very recent date and also certain considerations about the physical characteristics of the species, suggest that human beings are to some degree a mess, and that the rapid and immense development of symbolic and cultural capacities has left humans as beings for which no form of life is likely to prove entirely satisfactory, either individually or socially... [This contrasts with a] deeply teleological outlook [...] according to which there is inherent in each natural kind of thing an appropriate way for things of that kind to behave. On that view it must be the deepest desire [...] of human beings to live in the way that is in the objective sense appropriate to them ... The first and hardest lesson of Darwinism, that there is no such teleology at all, and that there is no orchestral score provided from anywhere according to which human beings have a special part to play, still has to find its way fully into ethical thought. ${ }^{19}$

The phrase 'to some degree a mess' flags up the fact that 'human

19 Bernard Williams, Making Sense of Humanity (Cambridge: Cambridge University Press, 1995), pp. 109-110; emphasis supplied. The importance of this passage is well brought out in David McPherson's illuminating paper 'Cosmic Outlooks and NeoAristotelian Virtue Ethics', International Philosophical Quarterly, Vol. 55, no. 2 (June 2015), pp. 197-215. 
nature' can, for those who follow Williams, no longer be thought of as foundational for an objective conception of the good and meaningful life. On the contrary, evolution has landed us, as Williams puts it elsewhere, with an 'ill assorted bricolage of powers and instincts' ${ }^{20}$ a ragbag of desires and dispositions and capacities which can be utilized in many possible ways, without anyone being entitled to declare that such or such a usage is objectively preferable. And the upshot will be, given the demise of objective teleology in our post-Darwinian world, that finding gratification in, for example, domination, or a Nietzschean will to power, or individual creativity that rides roughshod over the feelings and entitlements of others, or any such route to self-realization, may be as 'valid' as those modes of living which foster respect and enhance the rational nature of one's fellow humans - which latter modes are advocated, rightly in my view, by Metz. But my siding with Metz here does not assuage my philosophical qualm: that his notions of 'fundamentality' and 'fundamental conditions of human existence' are ones that he may not be entitled to use in the way he does, namely to underwrite the objectivity of the recipe he favours for the good and meaningful life. For in a Godless universe, which consists at its deepest essential level in a purposeless physical nexus with no guiding teleology, our human nature has no ultimate telos which could play the required normative role.

A theistic perspective, by contrast (which Metz of course rejects, but which the whole direction of his thinking, if I am right, implicitly cries out for) does clearly imply that our human nature is, in principle, structured towards a telos, however often we may resist it, or fall short of attaining it. And central to understanding this, for the theist, will be an acknowledgement of the significance of those distinctive and 'fundamental' intellectual and moral capacities of which we find ourselves possessed: an acknowledgement that what has happened on this planet (and for all we know elsewhere in the universe) is, in Thomas Nagel's significant phrase, 'the development of consciousness into an instrument of transcendence that can grasp objective reality and objective value. ${ }^{21}$ And what this will mean, on the theistic view, is that

${ }^{20}$ Bernard Williams, 'Replies', in J. Altham and R. Harrison (eds.), World, Mind, and Ethics (Cambridge: Cambridge University Press, 1995), p. 199; cited in McPherson, 'Cosmic Outlooks'.

${ }^{21}$ Thomas Nagel, Mind and Cosmos (Oxford: Oxford University Press, 2012) p. 85. 
among our 'rather ill-sorted bricolage of powers and instincts', there is a fundamental awareness of the good, a responsiveness to something objective that is not merely a projection of our various contingently evolved inclinations and preferences, and that the meaning of life for human beings must lie in our orienting ourselves towards that good. Theism may be unfashionable in the current philosophical climate, but if the argument of this paper has been on the right lines, it succeeds in finding a home for certain very fundamental human intuitions about meaning and objective value which it will be very hard to accommodate adequately within the prevailing naturalist worldview. 